\title{
THE INFLUENCE OF AZA-SUBSTITUTION ON THE AROMATICITY OF SUMANENE
}

\author{
MIHAI MEDELEANU ${ }^{\mathrm{a}}$, RALUCA POP ${ }^{\mathrm{b} *}$, MIHAIELA ANDONI ${ }^{\mathrm{b}}$, \\ MIRCEA V. DIUDEA ${ }^{c *}$
}

\begin{abstract}
The influence of aza-substitution on sumanene and $\mathrm{C}_{52}$ fullerene was investigated. Various substitution patterns, derived for the structures of pyrrole, indolizine and pyridine have been proposed and aromaticity indices like HOMA, NICS, delocalization indices PDI and FLU were considered, at B3LYP/6-311+G(d) level of theory. The results outlined an enhanced aromatic character for the sumanene derivatives where similar aza-substitution patterns as encountered in pyrrole and indolizine have been considered.
\end{abstract}

Keywords: sumanene, fullerene, aromaticity, aza-substitution

\section{INTRODUCTION}

During the last decades, specific properties of fullerenes - mainly due to their extended $\pi$ electron system - attracted a continuous interest of scientists, as well as for their possible precursors. The presence of one (or more) isovalent atoms like nitrogen may modify the extended $\pi$ electron system. Literature survey outlines a number of studies regarding the effects of heteroatoms doping the carbon-based nanomaterials. This way, researches regarding the curvature evolution and cross-linkage in carbon nitride have demonstrated that incorporation of $\mathrm{N}$ atom determines an increased reactivity of the $\mathrm{C}$ atoms in the vicinity of heteroatom, the most stable isomer being the one containing one $\mathrm{N}$ atom per pentagon [1]. Investigations of the structure

a University POLITEHNICA Timisoara, Faculty of Industrial Chemistry and Environmental Engineering, 300006 Timisoara, Romania

b University of Medicine and Pharmacy "Victor Babeş" Timisoara, Faculty of Pharmacy, Eftimie Murgu Square 2, 300041 Timişoara, Romania

c Department of Chemistry, Faculty of Chemistry and Chemical Engineering, Babes-Bolyai University, 400028 Cluj, Romania

*Corresponding authors: pop.raluca@umft.ro; diudea@gmail.com 
and stability of heteroannulated [8-10] circulenes with N, P and As atoms have proved the influence of steric factors and heteroatom electronegativity on the $\pi$ electron delocalization [2]. Also, a study, regarding the effects of $\mathrm{N}$ doping on the electronic properties of a small carbon chain with distinct $\mathrm{sp}^{2}$ termination, showed that incorporation of a nitrogen atom influences the conformation, charge distribution and the spin states of structures consisting in corannulene/ coronene-like pieces connected by atomic chains [3]. Another theoretical investigation of nitrogen disubstituted corannulenes suggested an increased stability for the isomer containing two $\mathrm{N}$ atoms within the benzene ring, in para position [4].

Concerning the properties of doped fullerenes, their electronic behavior was reported in [5]; then properties of $\mathrm{C}_{59} \mathrm{X}$-type fullerenes (where $X=B, N$, $\mathrm{Al}, \mathrm{Si}, \mathrm{P}, \mathrm{Ga}, \mathrm{Ge}$ and As) [6], applications of N-doped carbon nanotubes [7], electron delocalization and dimerization in solid $\mathrm{C}_{59} \mathrm{~N}$ doped $\mathrm{C}_{60}$ fullerene [8], structure and electronic properties of heterofullerene $\mathrm{C}_{30} \mathrm{~B}_{15} \mathrm{~N}_{15}$ [9], stability of boron nitride fullerenes [10], also small fullerenes doped with boron and nitrogen [11] have been reported. Possible isomers of heterofullerenes of the type $X_{n} C_{20-n}(X=B, N, P$ and $n=2,4,5,6,10)$ were also studied [12]. The stability of compounds is directly related to the number and type of heteroatoms, as well as to the substitution pattern, the $\mathrm{N}$ - and P- doped fullerenes being thermodynamically favoured in comparison to their boron analogues [16]. In another study [13], various isomers of $\mathrm{N}$-doped fullerenes of the type $\mathrm{C}_{42} \mathrm{~N}_{18}$ and $\mathrm{C}_{40} \mathrm{~N}_{20}$ have been investigated, including structures with separated $\mathrm{N}$ atoms and nitrogen belts. The results outlined a reasonable stability for the compounds with a belt of $\mathrm{N}$ atoms, with possible applications in molecular electronics [13].

Researches regarding the influence of hetero-substitution of carbonbased nanomaterials have also been extended to graphenes and nanotubes; properties like magnetism and mobility [14], sensing applications [15], electronic and optical properties [16] have been studied.

Our previous studies dealt with the investigation of aromaticity of fullerenes and their precursors [17-18], as well as of their $\mathrm{N}$ - and P-substituted analogues [19-22]. A comparison between the calculated properties of both fullerenes and circulene-type precursors was made.

\section{DATA SET}

The present paper is focused on the influence of aza-substitution on both sumanene and $\mathrm{C}_{52}$ derivatives, containing a sumanene patch. Three substitution patterns, derived from the structures of pyrrole, indolizine and pyridine, are proposed. 
<smiles></smiles>

Pyrrole (I)<smiles>c1ccn2cccc2c1</smiles>

Indolizine (II-III)<smiles>c1ccncc1</smiles>

Pyridine (IV)

Figure 1. Substitution patterns: I - pyrrole type; II and III - indolizine type; IV - pyridine type

The structures of investigated sumanene and its aza-derivatives are depicted in Figure 2; the same pattern has been employed for the design of aza-fullerenes $\mathrm{C}_{49} \mathrm{~N}_{3}$ :

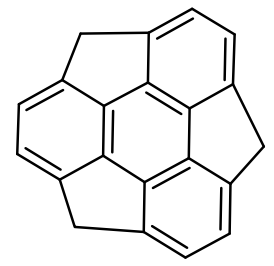

Sumanene $\left[6 .(5,6)_{3}\right]$<smiles>c1cc2[nH]c3ccc4[nH]c5ccc6[nH]c1c1c2c3c4c5c61</smiles>

।<smiles></smiles>

II<smiles></smiles>

III<smiles>c1nc2c3c4c1Cc1cnc5c(c14)c1c(ncc(c31)C2)C5</smiles>

IV

Figure 2. Aza-substitution patterns used throughout the study

Observe the two different indolizine-type patterns: II - with the $\mathrm{N}$ atom placed "outer" of the pentagon-hexagon pair, and III - with the $\mathrm{N}$ atom in "inner" position. While the all-Carbon structure II is bowl-shaped, the presence of $\mathrm{N}$ atoms leads to a planar geometry. Geometry optimization and vibrational analysis showed that structures I, III and IV are true minima, but the compound II is a transition state (with an imaginary frequency).

\section{RESULTS AND DISCUSSION}

Various local aromaticity descriptors, like the geometric index HOMA, magnetic index NICS, reactivity descriptors (condensed Fukui functions), and cohesion energy have been computed. 


\section{Geometric index}

The optimized structures of the investigated aza-sumanene derivatives are shown in Figure 3. Values of the convex angle for the sumanene and its four aza-derivatives are listed in Table 1.
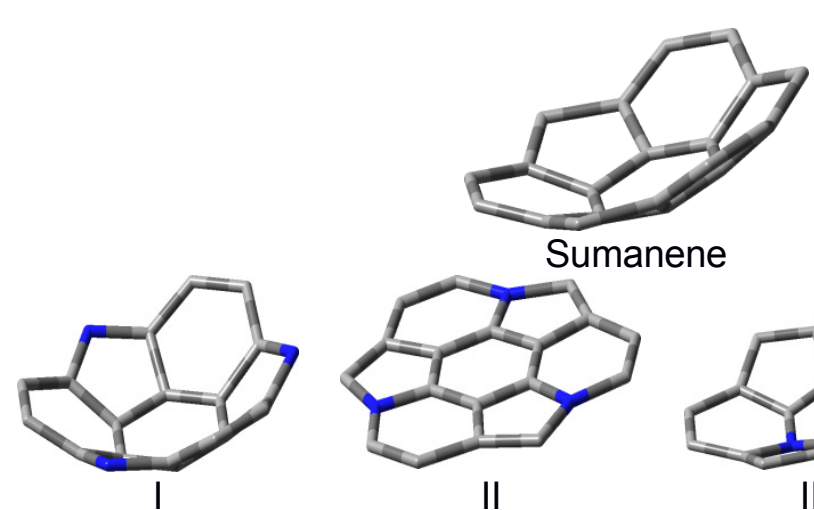

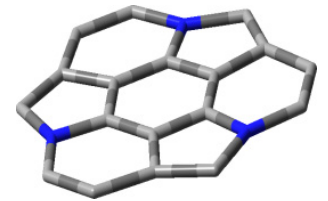

II

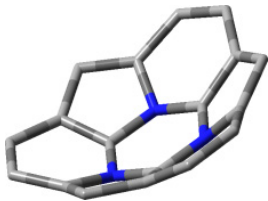

III

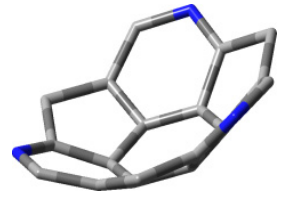

IV

Figure 3. Optimized geometries (B3LYP/6-311+G(d)) of sumanene and its aza-derivatives

Table 1. Values of the convex angle in the bowl-shaped sumanene derivatives

\begin{tabular}{cc}
\hline Structure & Convex angle \\
\hline All C & 152.8 \\
I & 146.7 \\
II & 0.0 \\
III & 151.3 \\
IV & 145.1 \\
\hline
\end{tabular}

Table 2. HOMA index computed for the core and 5- and 6-membered rings

\begin{tabular}{cccccc}
\hline HOMA & Sumanene & I-aza & II-aza & III-aza & IV-aza \\
\hline core & 0.703 & 0.853 & 0.728 & 0.953 & 0.738 \\
6- ring & 0.862 & 0.898 & 0.068 & 0.364 & 0.784 \\
5- ring & 0.472 & 0.800 & 0.354 & 0.588 & 0.624 \\
\hline
\end{tabular}

The following observations can be made:

- I-type aza-substitution leads to an improvement of the HOMA index value (compared to the bare sumanene); the most significant difference appears for the 5-membered ring, when the substitution of $\mathrm{sp}^{3} \mathrm{C}$ atom with $\mathrm{N}$ leads to a bond shortening from $1.562 \AA$ to $1.420 \AA$; 
- Il-type aza substitution is characterized by lower values of the HOMA index for the outer rings, due to the planar conformation;

- III-type substitution: the alternation carbon-nitrogen in the core ring results in the highest value of the HOMA index;

- IV-type substitution shows the smallest differences compared to the reference sumanene molecule.

- The main stabilization seems to appear at the ring bearing $\mathrm{N}$ atom and it is higher at the core hexagonal ring (in I-aza and III-aza substitution).

\section{Magnetic index}

Data on nucleus independent carbon shift NICS are listed in Table 3.

Table 3. NICS $(0)$ values computed for the core and petals of sumanene and aza-sumanenes (B3LYP/6-311+G(d))

\begin{tabular}{cccccc}
\hline Position & Sumanene & I-aza & II-aza & III-aza & IV-aza \\
\hline core & -3.01 & 1.05 & -8.10 & 15.39 & -3.64 \\
\hline 6-ring & -9.03 & -11.96 & -3.34 & 0.81 & -8.15 \\
& -9.11 & -11.96 & -3.55 & 0.90 & -8.10 \\
& -9.18 & -12.29 & -3.34 & 0.84 & -8.08 \\
\hline 5- rings & 2.47 & -8.60 & -15.99 & -10.74 & 1.88 \\
& 2.41 & -8.87 & -15.87 & -11.00 & 1.84 \\
& 2.47 & -8.78 & -15.89 & -10.87 & 1.84 \\
\hline
\end{tabular}

The results are in good agreement with the predictions of the geometric index HOMA; this way, similar values have been obtained for the bare sumanene and for the IV-aza substitution (that proves the small influence of replacing by nitrogen one $C$ atom from outer 6-membered rings). The presence of $\mathrm{N}$ atom in the 5-membered rings (similar to pyrrole) leads to their "aromatization" (see the negative NICS values). The negative values of NICS index obtained for all the rings of II-type aza-sumanene can be attributed to the stronger electron delocalization, favoured by the planar structure. Again, there are small differences between sumanene and IVtype aza-substitution.

\section{Delocalization indices}

Smallest values of the FLU index (highest aromaticity) have been obtained for the petal 6-ring of sumanene and IV-type aza-sumanene, proving again the similarity of these two molecules. The presence of $\mathrm{N}$ atom within the 5-membered ring of I-, II- and III-aza-sumanenes promotes an increase in their aromaticity. 
A lower local aromaticity has been obtained for the 6-membered rings of III-aza-sumanene, result that is in good agreement with $\mathrm{NICS}(0)$ values. Concerning the calculated PDI values for the 6-membered rings, closer results to the standard PDI for benzene, 0.105 , have been obtained for the 6outer cycles of sumanene and IV-aza-sumanene. Lowest PDI values are attributed to the 6-core of I- and III-aza-sumanenes and correlate well with FLU and NICS $(0)$ results.

Graphical representation of the Electron Localization Function is shown in Appendix (Figure A1); it outlines the similarity between the structures of sumanene and the aza-derivative IV, as well as the differences among the planar structure of aza-sumanene II and the other bowl-shaped compounds.

Table 4. FLU and PDI results for sumanene and its aza-derivatives

\begin{tabular}{cccc}
\hline Compound & Cycles & FLU & PDI \\
\hline \multirow{2}{*}{ Sumanene } & core & 0.034 & 0.030 \\
& 6-ring & 0.008 & 0.082 \\
& 5-ring & 0.054 & - \\
\hline \multirow{3}{*}{ I-aza-sumanene } & core & 0.032 & 0.029 \\
& 6-ring & 0.012 & 0.068 \\
& 5-ring & 0.039 & - \\
\hline \multirow{3}{*}{ II-aza-sumanene } & core & 0.021 & 0.046 \\
& 6-ring & 0.034 & 0.041 \\
& 5-ring & 0.033 & - \\
\hline \multirow{3}{*}{ III-aza-sumanene } & core & 0.059 & 0.015 \\
& 6-ring & 0.039 & 0.041 \\
& 5-ring & 0.030 & - \\
\hline \multirow{2}{*}{ IV-aza-sumanene } & core & 0.034 & 0.030 \\
& 6-ring & 0.009 & 0.082 \\
\hline
\end{tabular}

\section{Reactivity indices}

In order to investigate the effect of $\mathrm{N}$ incorporation on the reactivity of carbon atoms, the condensed Fukui functions (for an electrophilic attack) have been computed (numbering of atoms in the aza-patches is shown in Figure 4). 
<smiles></smiles>

Sumanene $\left[6 .(5,6)_{3}\right]$<smiles></smiles><smiles></smiles>

II

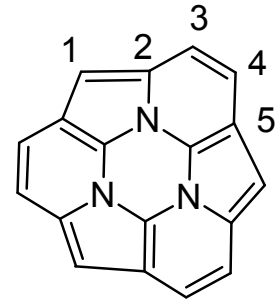

III

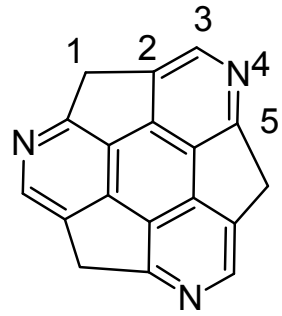

IV

Figure 4. Atom numbering of sumanene and aza-sumanene moieties

The results, listed in Table 5, show an increased reactivity only for the $\mathrm{C}$ atoms from structure III, less significant results being obtained for the compounds where the $\mathrm{N}$ atom is placed in "outer" rings.

Table 5. Condensed Fukui functions computed for an electrophilic attack

\begin{tabular}{cccccc}
\hline$f-($ HOMO) & Sumanene & I-aza & II-aza & III-aza & IV-aza \\
\hline 1 & 0.370 & - & 0.078 & 0.272 & 0.066 \\
2 & 0.174 & 0.078 & 0.003 & 0.227 & 0.094 \\
3 & 0.182 & 0.106 & 0.010 & 0.055 & 0.060 \\
4 & 0.054 & 0.127 & 0.002 & 0.215 & - \\
5 & 0.149 & 0.184 & - & 0.431 & 0.053 \\
\hline
\end{tabular}

5. Global parameters of the investigated fullerenes: HOMOLUMO gap, singlet-triplet gap and cohesive energy.

Keeping in mind the above-mentioned aza-patches, the structures including these patches in the molecule of $\mathrm{C}_{52}$ fullerene (isomer with four joint sumanene patches, D2 symmetry), namely aza-fullerenes $\mathrm{C}_{49} \mathrm{~N}_{3}$ have been designed. 

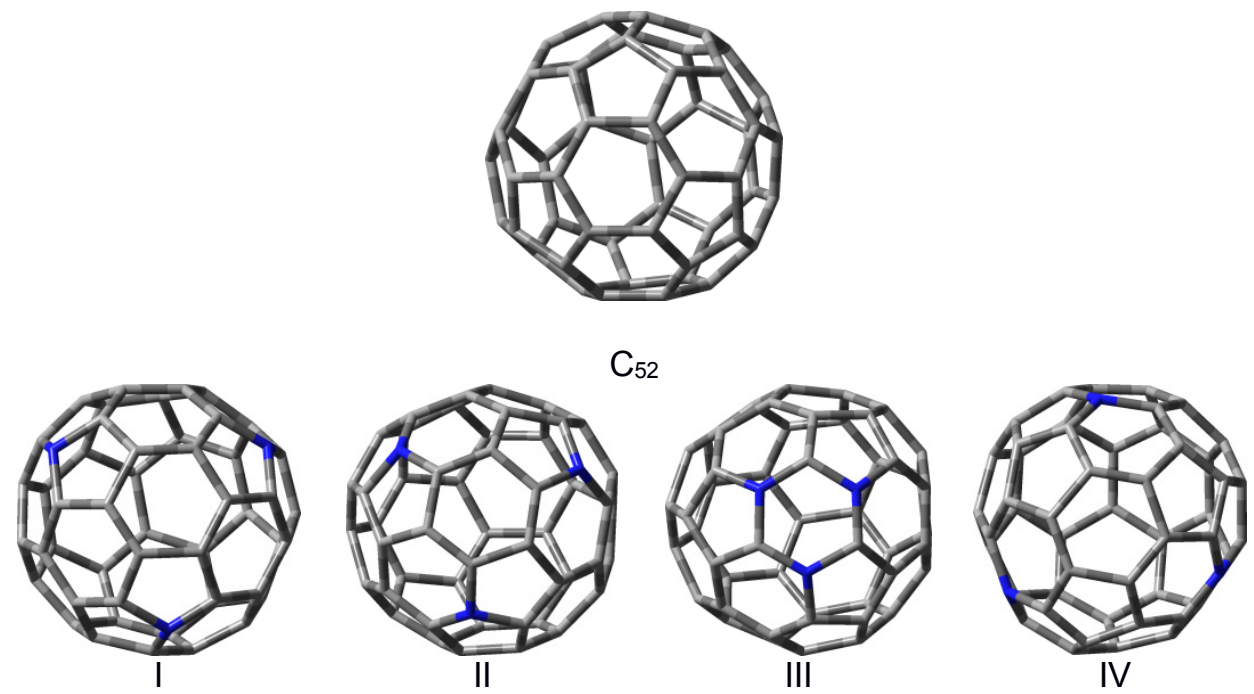

Figure 5. Optimized geometry (B3LYP/6-311G) of $\mathrm{C}_{52}$ and $\mathrm{C}_{49} \mathrm{~N}_{3}$ fullerenes

Computation of global parameter HOMO-LUMO gap for both sumanene and $\mathrm{C}_{52}$ derivatives has shown that, the III-aza substitution leads to the less stable compounds (Table 6). The trend within the sumanene series follows the results of magnetic and geometric indices, which outlined the similarities between the all-carbon compound and the IV-aza substitution.

Table 6. HOMO-LUMO gap of sumanene and $\mathrm{C}_{52}$, and of their aza-derivatives

\begin{tabular}{ccc}
\hline HL gap $(e V)$ & Sumanene & $\mathrm{C}_{52}$ \\
\hline All carbon & 4.63 & 1.09 \\
I & 3.94 & 0.89 \\
II & 3.62 & 0.89 \\
III & 3.47 & 0.62 \\
IV & 4.63 & 0.91 \\
\hline
\end{tabular}

Regarding the $\mathrm{C}_{52}$ derivatives, smaller difference appear among $\mathrm{C}_{52}$ and $\mathrm{C}_{49} \mathrm{~N}_{3}$ characterized by I-, II- and IV-aza-substitution.

Computation of the singlet-triplet ST gap, another important parameter for characterizing nanomaterials, shown a significant decrease for the $\mathrm{N}$ substituted fullerenes and especially for the III $\mathrm{C}_{49} \mathrm{~N}_{3}$ (Table 7). 
Table 7. ST gap of $\mathrm{C}_{52}$ and $\mathrm{C}_{49} \mathrm{~N}_{3}$ compounds (B3LYP/6-311+G(d))

\begin{tabular}{cc}
\hline Compound & ST gap (eV) \\
\hline $\mathrm{C}_{52}$ & 0.257 \\
$\mathrm{C}_{49} \mathrm{~N}_{3}$ (I) & 0.049 \\
$\mathrm{C}_{49} \mathrm{~N}_{3}$ (II) & 0.060 \\
$\mathrm{C}_{49} \mathrm{~N}_{3}$ (III) & 0.008 \\
$\mathrm{C}_{49} \mathrm{~N}_{3}$ (IV) & 0.061 \\
\hline
\end{tabular}

Another parameter that is widely used for characterizing the stability of nanomaterials, like fullerenes, is the cohesive energy, calculated according to the equation:

$$
E_{\text {coh (at) }}=-\left(E_{\text {total }}-n_{C} E_{C}-n_{N} E_{N}\right) /\left(n_{C}+n_{N}\right)
$$

The results listed in Table 8 suggest no differences among the four types of aza-substitution herein proposed; however, with respect to the homosumanene, the aza-substitution seems to decrease the cohesive energy.

Table 8. Cohesive energy computed for $\mathrm{C}_{52}$ and $\mathrm{C}_{49} \mathrm{~N}_{3}$ fullerenes

\begin{tabular}{cc}
\hline Compound & $\mathrm{E}_{\text {coh }}($ a.u. $)$ \\
\hline $\mathrm{C}_{52}$ & 0.307 \\
$\mathrm{C}_{49} \mathrm{~N}_{3}$ (I) & 0.282 \\
$\mathrm{C}_{49} \mathrm{~N}_{3}$ (II) & 0.282 \\
$\mathrm{C}_{49} \mathrm{~N}_{3}$ (III) & 0.280 \\
$\mathrm{C}_{49} \mathrm{~N}_{3}$ (IV) & 0.280 \\
\hline
\end{tabular}

\section{Properties of aza-fullerenes $\mathrm{C}_{49} \mathrm{~N}_{3}$ : polarizability, hyperpolarizability, magnetizability and dipole moment}

Properties like polarizability and hyperpolarizability, magnetizability and the dipole moment, playing an important role in the behaviour of nanomaterials, are significantly influenced by the four types of aza-substitution (Table 9).

Table 9. Polarizability, hyperpolarizability magnetizability and dipole moment of the aza-fullerenes (BLYP/TZ2P)

\begin{tabular}{ccccc}
\hline Compound & $\begin{array}{c}\text { Polarizability } \\
\text { (a.u.) }\end{array}$ & $\begin{array}{c}\text { Hyperpolarizability } \\
\text { (a.u.) }\end{array}$ & $\begin{array}{c}\text { Magnetizability } \\
\text { (a.u.) }\end{array}$ & $\begin{array}{c}\text { Dipole } \\
\text { moment }\end{array}$ \\
\hline $\mathrm{C}_{49} \mathrm{~N}_{3}$ (I) & 459.19 & 563.39 & -191.26 & 0.579 \\
$\mathrm{C}_{49} \mathrm{~N}_{3}$ (II) & 465.18 & 546.07 & -211.26 & 1.307 \\
$\mathrm{C}_{49} \mathrm{~N}_{3}$ (III) & 472.25 & 674.61 & -250.99 & 2.112 \\
$\mathrm{C}_{49} \mathrm{~N}_{3}$ (IV) & 469.64 & 521.93 & -209.82 & 1.465 \\
\hline
\end{tabular}


Also, two types of atomic charges, namely CM5 and the Voronoi Density Deformation (VDD) charges, have been computed. The atomic charges CM5 [33] (Charge Model 5) show an increased accuracy in predicting the dipole moment and are based on the Hirshfeld analysis combined with a parametrization method. The VDD method [34, 35] relies on the dividing of space into non-overlapping atomic areas and the consequent calculation of the deformation density of these cells. Figure A2 (see Appendix) depicts only the charge values of the nitrogen atoms.

\section{CONCLUSIONS}

The influence of aza-substitution in sumanene and $\mathrm{C}_{52}$ fullerene on their stability/aromaticity was investigated; a bowl-shaped polycyclic aromatic hydrocarbon, four aza-substitution types derived from the structures of pyrrole, indolizine and pyridine have been considered. Structures of azafullerenes $\mathrm{C}_{49} \mathrm{~N}_{3}$, where the aza-substitution follows the same pattern as in case of sumanene, have been optimized and a series of global parameters were computed for their characterization. Calculation of the local aromaticity indices like NICS and HOMA, as well as delocalization indices PDI and FLU outlined the enhanced aromatic character of sumanene derivatives where the 5-membered ring was replaced by a pyrrole moiety (I-aza-substitution type). Also, an increase of the aromaticity has been obtained for the II-azasumanene, where the outer 5 - and 6-membered rings have a common nitrogen atom at the outer junction (similar to the indolizine ring). No significant variations of aromaticity (compared to the values obtained for the all-carbon sumanene) have been obtained for the structure IV (where the aza-substitution occurs as in the pyridine moiety).

The proposed structures of fullerenes $\mathrm{C}_{49} \mathrm{~N}_{3}$ were characterized by smaller $\mathrm{HL}$ gap and singlet-triplet gap for the III-C ${ }_{49} \mathrm{~N}_{3}$ structure, while the computations of cohesive energy lead to similar values for all the four investigated fullerenes. As an overall conclusion, the III-aza patch seems to induce the most reactivity among all the studied aza-containing structures.

\section{COMPUTATIONAL DETAILS}

All the computations regarding the sumanene and its derivatives have been carried out at B3LYP/6-311+G(d) level of theory. Geometry optimization and vibrational analysis of the fullerene $\mathrm{C}_{52}$ and the corresponding azaderivatives have been performed by using the basis set 6-311G. The obtained 
structures were refined by performing a single point computation at B3LYP/6$311+G(d)$ level of theory. The calculations of the magnetic index, reactivity descriptors, and delocalization indices were performed by means of the same combination B3LYP/6-311+G(d). The delocalization indices were computed with Multiwfn_3.3.4 software [23], while Gaussian 09W [24] has been employed for the computations of sumanene and its aza-derivatives, as well as for the geometry optimizations of the $\mathrm{C}_{52}$ and $\mathrm{C}_{49} \mathrm{~N}_{3}$. ADF2014 software [25-27] has been employed for the calculation of polarizability $[28,29]$, hyperpolarizability [30,31], magnetizability [32] and dipole moment. Also, the atomic charges CM5 [33] and VDD [34,35] have been computed by means of ADF2014. For the computations performed with the ADF2014 software, the combination of BLYP with basis set TZ2P [36] has been used.

\section{REFERENCES}

1. G.K. Gueorguiev, J. Neidhardt, S. Stafstrom, L. Hultman, Chemical Physics Letters., 2005, 410, 228.

2. T. N. Gribanova, N.S. Zefirov, V. I. Minkin, Pure and Applied Chemistry., 2010, 82(4), 1011.

3. R.B. dos Santos, R. Rivelino, F. de Brito Mota, G.K. Gueorguiev, Physical Review B, 2011, 84, 075417.

4. P.A. Denis, Journal of Molecular Structure: THEOCHEM, 2008, 865, 8.

5. L. Forro, L. Mihaly, Reports on Progress in Physics, 2001, 64, 649.

6. H. Bai, W. Ji, X. Liu, L. Wang, N. Yuan, Y. Ji, Journal of Chemistry, 2013, 571709.

7. P. Ayala, R. Arenal, M. Rummeli, A. Rubio, T. Pichler, Carbon, 2010, 48, 575.

8. A. Rockenbauer, G. Csany, F. Fulop, S. Garaj, L. Korecz, R. Lukacs, F. Simon, L. Forro, S. Pekker, A. Janossy, Physical Review Letters, 2005, 94, 066603.

9. S. Erkoc, Journal of Molecular Structure: THEOCHEM, 2004, 684, 117.

10. R.J.C. Batista, M.S.C. Mazzoni, H. Chacham, Chemical Physics Letters, 2006, 421, 246.

11. L. Viani, M. C. dos Santos, Solid State Communications. 2006, 138, 498.

12. M.Z. Kassaee, F. Buazar, M. Koohi, Journal of Molecular Structure: THEOCHEM, 2010, 940, 19.

13. A.-R. Nekoei, S. Haghgoo, Computational and Theoretical Chemistry, 2015, 1067, 148.

14. Y. Ma, A.S. Foster, A.V. Krasheninnikov, R.M. Nieminen, Physical Review B, 2005, 72, 205416.

15. K.P. Prathish, M.M. Barsan, D. Geng, X. Sun, C.M.A. Brett, Electrochimica Acta, 2013, 114, 533.

16. P. Nath, S. Chowdhury, D. Sanyal, D. Jana, Carbon, 2014, 73, 275.

17. R. Pop, M. Medeleanu, M.V. Diudea, B. Szefler, J. Cioslowski, Central European Journal of Chemistry, 2014, 12(1), 90.

18. R. Pop, M. Medeleanu, M.V. Diudea, B. Szefler, J. Cioslowski, Central European Journal of Chemistry, 2013, 11(4), 527. 
19. R. Pop, M. Andoni, Iulia Pausescu, Mihai Medeleanu, Revista de Chimie, 2013, 64(9), 942.

20. R. Pop, J. Van Staden, M. Diudea, Z. Naturforschung A, 2015, 70(3), 171.

21. R. Pop, M. Diudea, M. Medeleanu, M. Andoni, Studia Universitatis BabesBolyai Chemia, 2015, 60(1), 195.

22. R. Pop, M. Andoni, J. Van Staden, I. Păuşescu, M. Medeleanu, Digest Journal of Nanomaterials and Biostructures, 2013, 8(4), 1739.

23. T. Lu, F.J. Chen, Journal of Computational Chemistry, 2012, 33, 580.

24. Gaussian 09, Revision B.01, M.J. Frisch, G.W. Trucks, H.B. Schlegel, G.E. Scuseria, M.A. Robb, J.R. Cheeseman, G. Scalmani, V. Barone, B. Mennucci, G.A. Petersson, H. Nakatsuji, M. Caricato, X. Li, H.P. Hratchian, A.F. Izmaylov, J. Bloino, G. Zheng, J.L. Sonnenberg, M. Hada, M. Ehara, K. Toyota, R. Fukuda, J. Hasegawa, M. Ishida, T. Nakajima, Y. Honda, O. Kitao, H. Nakai, T. Vreven, J.A. Montgomery, Jr., J.E. Peralta, F. Ogliaro, M. Bearpark, J.J. Heyd, E. Brothers, K.N. Kudin, V.N. Staroverov, T. Keith, R. Kobayashi, J. Normand, K. Raghavachari, A. Rendell, J.C. Burant, S.S. Iyengar, J. Tomasi, M. Cossi, N. Rega, J.M. Millam, M. Klene, J.E. Knox, J.B. Cross, V. Bakken, C. Adamo, J. Jaramillo, R. Gomperts, R.E. Stratmann, O. Yazyev, A.J. Austin, R. Cammi, C. Pomelli, J.W. Ochterski, R.L. Martin, K. Morokuma, V.G. Zakrzewski, G.A. Voth, P. Salvador, J.J. Dannenberg, S. Dapprich, A.D. Daniels, O. Farkas, J.B. Foresman, J.V. Ortiz, J. Cioslowski, and D.J. Fox, Gaussian, Inc., Wallingford CT, 2010.

25. G. Te Velde, F.M. Bickelhaupt, E.J. Baerends, C. Fonseca Guerra, S.J.A. van Gisbergen, J.G. Snijders and T. Ziegler, Journal of Computational Chemistry, 2001, 22, 931.

26. C. Fonseca Guerra, J.G. Snijders, G. Te Velde, E.J. Baerends, Theoretical Chemistry Accounts, 1998, 99, 391.

27. ADF2014, SCM, Theoretical Chemistry, Vrije Universiteit, Amsterdam, The Netherlands, http://www.scm.com.

28. S.J.A. van Gisbergen, J.G. Snijders, E.J. Baerends, Journal of Chemical Physics, 1995, 103, 9347.

29. S.J.A. van Gisbergen, J.G. Snijders, E.J. Baerends, Computer Physics Communications. 1999, 118, 119.

30. S.J.A. van Gisbergen, J.G. Snijders, E.J. Baerends, Journal of Chemical Physics, 1998, 109, 10644.

31. S.J.A. van Gisbergen, J.G. Snijders, E.J. Baerends, Physical Review Letters, 1997, 78, 3097.

32. M. Krykunov, J. Autschbach, Journal of Chemical Physics, 2007, 126, 24101.

33. A.V. Marenich, S.V. Jerome, C.J. Cramer, D.G. Truhlar, Journal of Chemical Theory and Computation, 2012, 8, 527.

34. G. Te Velde, Numerical integration and other methodological aspects of band structure calculations, in Chemistry. 1990, Vrije Universiteit: Amsterdam.

35. C. Fonseca Guerra, J.-W. Handgraaf, E. J. Baerends, F. M. Bickelhaupt, Journal of Computational Chemistry, 2004, 25, 189.

36. E. van Lenthe, E.J. Baerends, Journal of Computational Chemistry, 2003, 24, 1142. 


\section{APPENDIX}
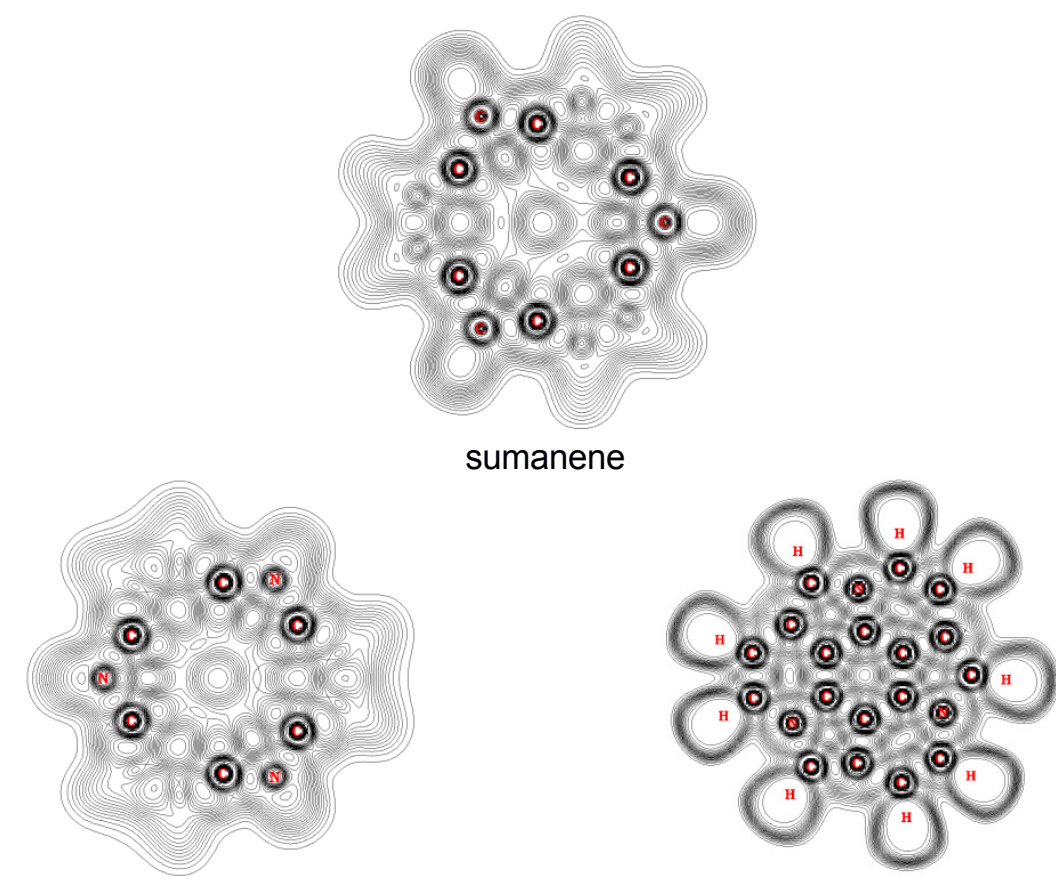

I-aza-sumanene
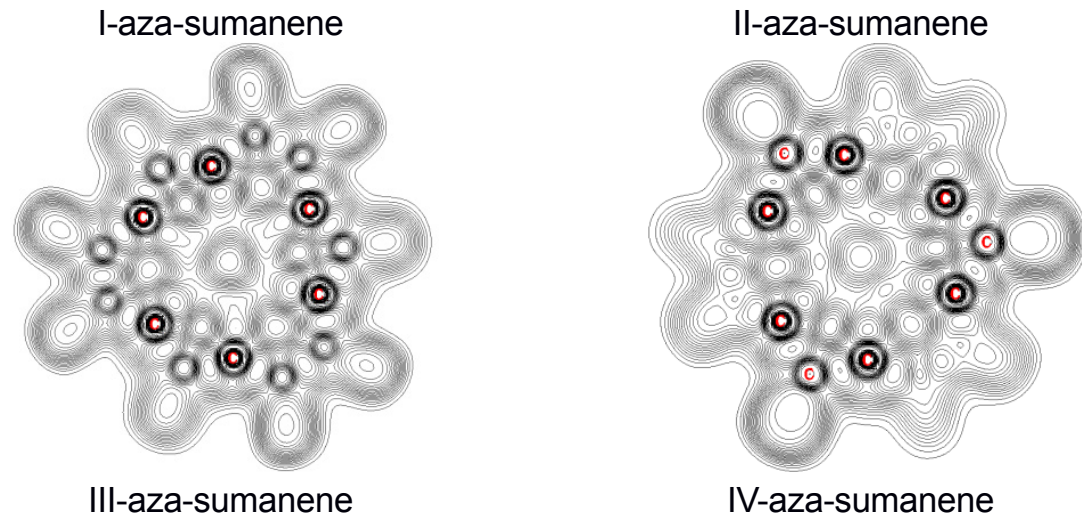

III-aza-sumanene

Figure A1. ELF (Electron Localization Function) computed for sumanene and the four aza-derivatives 

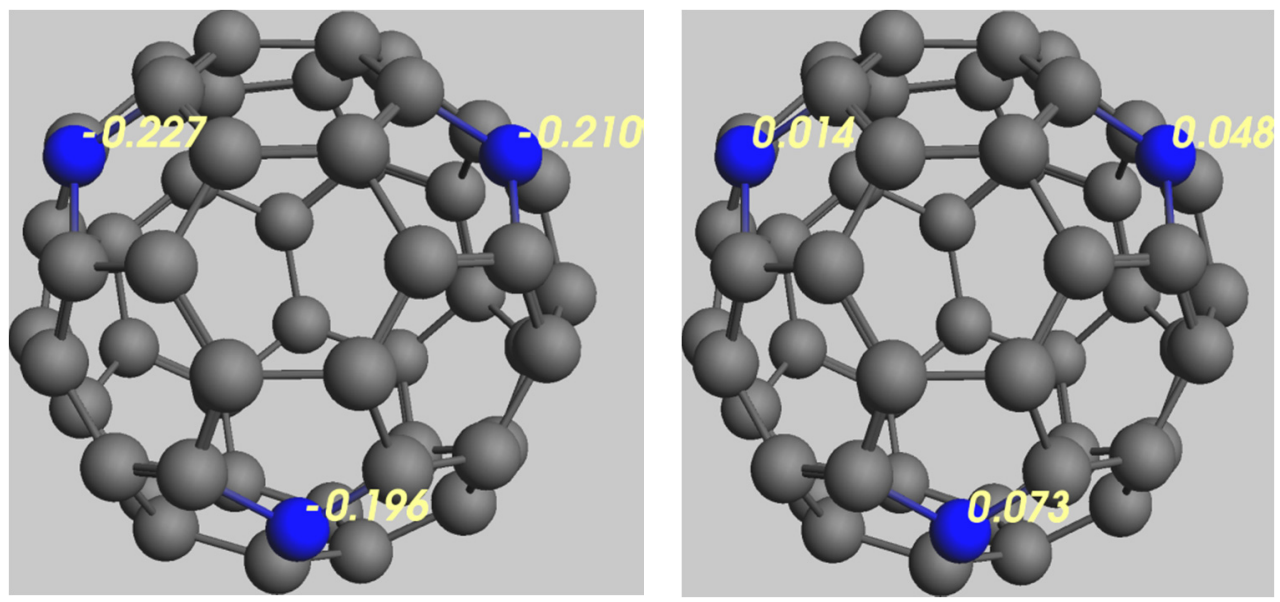

Atomic charges CM5 (left) and VDD (right) computed for $\mathrm{C}_{49} \mathrm{~N}_{3}$ (I)
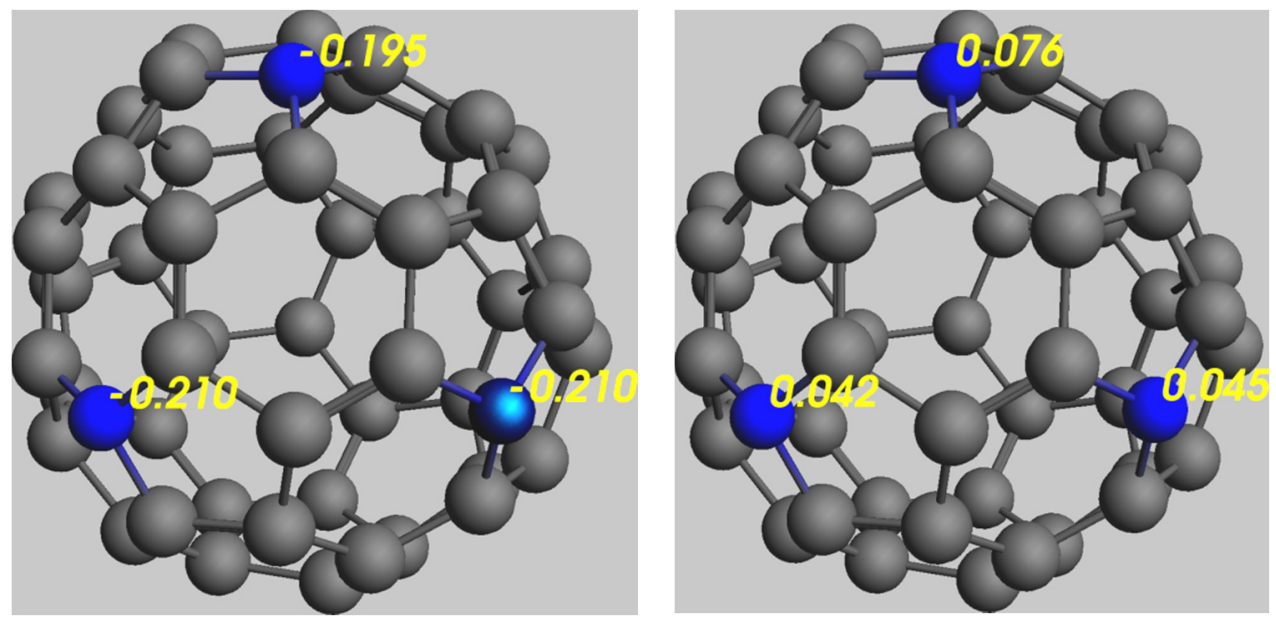

Atomic charges CM5 (left) and VDD (right) computed for $\mathrm{C}_{49} \mathrm{~N}_{3}$ (II)

Figure A2. CM5 atomic charges of the aza-fullerenes 

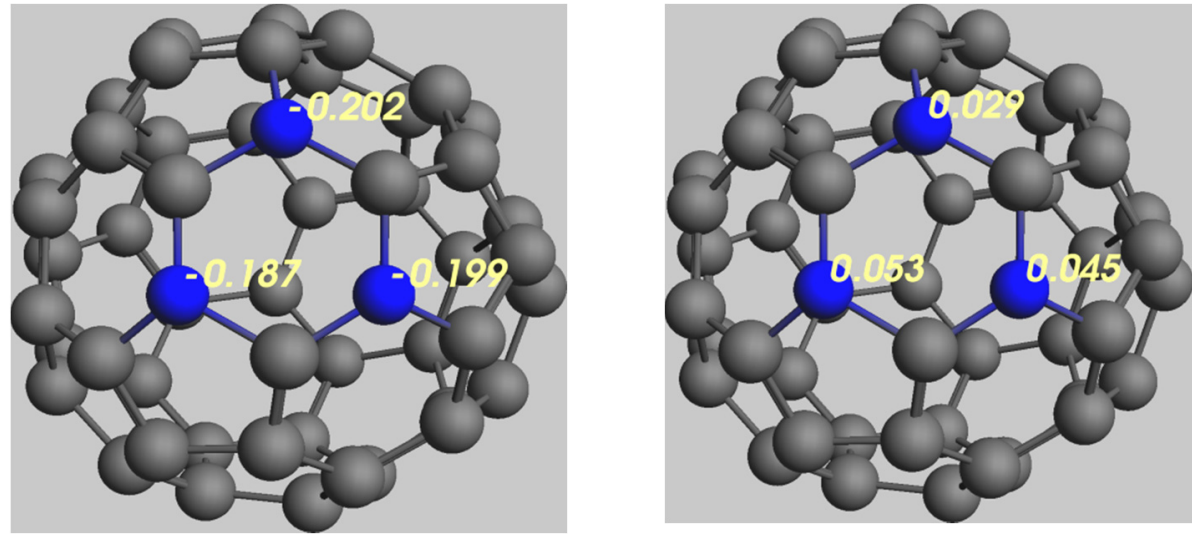

Atomic charges CM5 (left) and VDD (right) computed for $\mathrm{C}_{49} \mathrm{~N}_{3}$ (III)
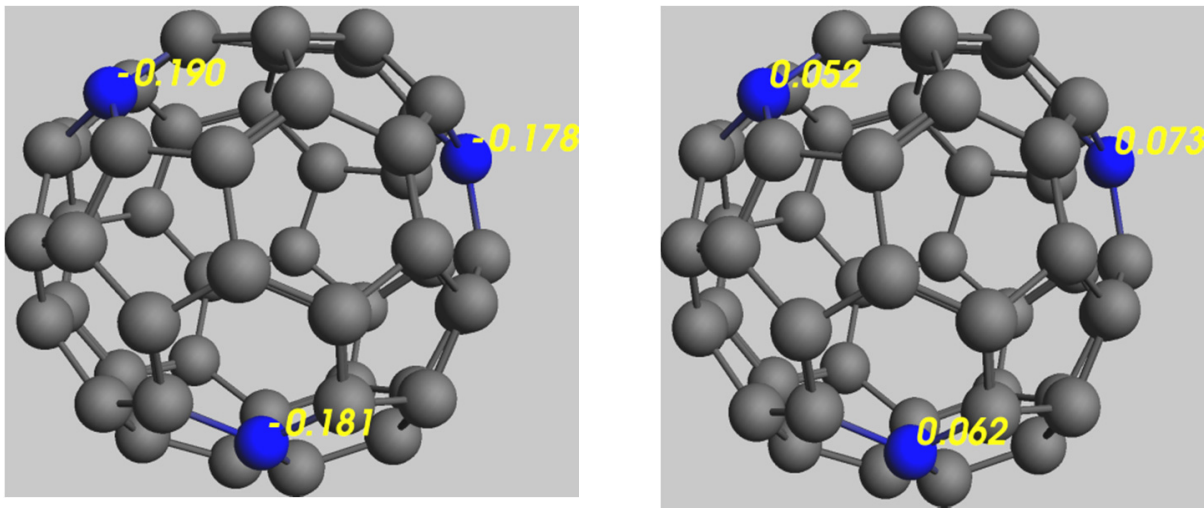

Atomic charges CM5 (left) and VDD (right) computed for $\mathrm{C}_{49} \mathrm{~N}_{3}$ (IV)

Figure A2 (continued). CM5 atomic charges of the aza-fullerenes 